\title{
Una primera aproximación al "An Essay in Defence of the Female Sex" (1696): su autoría, su estructura argumentativa y sus estrategias retóricas ${ }^{1}$
}

Resumen: El artículo ofrece un aproximación preliminar y parcial al panfleto feminista inglés "An Essay in Defence of the Female Sex" (1696). Luego de una breve introducción destinada a contextualizar la obra y un bosquejo de su estructura general, se procede al análisis más detenido de su primera mitad, reconstruyendo los argumentos sobre los cuales se funda la defensa del sexo femenino y mostrando de qué manera las conclusiones filosóficas más relevantes se articulan con una secuencia de discursos retóricos específicamente diseñados para un auditorio femenino. El artículo defiende la emergencia de una dicotomía naturaleza-historia que permite a la autora, por un lado, desenmascarar una situación de dominio masculino (críticamente reconocible hoy día como antecedente directo de las discusiones feministas contemporáneas) y, por el otro, ofrecer una vía retórica para la conformación y reconfiguración de un ethos y un pathos femenino.

Palabras clave: Judith Drake - Mary Astell - Naturaleza - Historia - Feminismo

\section{A first approach to "An Essay in Defence of the Female Sex" (1696): its authorship, its argumentative structure, and its rhetorical strategies}

\begin{abstract}
The article offers a preliminary and partial approach to the English feminist pamphlet "An Essay in Defence of the Female Sex" (1696). After a brief introduction aimed at contextualizing the work and providing an outline of its general structure, we proceed to a more detailed analysis of its first half, reconstructing the arguments on which the defense of the female sex is based, and showing how its most relevant philosophical conclusions articulate with a sequence of rhetorical speeches specifically designed for a female audience. The article claims the emergence of a nature-history dichotomy that allows the author, on the one hand, to unmask a situation of male dominance (that we can today critically recognize as a direct antecedent of contemporary feminist discussions) and, on the other, to offer a rhetorical pathway for the conformation and reconfiguration of a feminine ethos and pathos.
\end{abstract}

Keywords: Judith Drake - Mary Astell - Nature - History - Feminism

\footnotetext{
${ }^{1}$ Este trabajo fue presentado en el I Encontro Argentina-Brasil sobre Estudos do Século XVIII/I Encuentro Argentina-Brasil sobre Estudios del Siglo XVIII, realizado en octubre de 2020.

2 Universidad de Buenos Aires (UBA) - Consejo Nacional de Investigaciones Científicas y Técnicas (CONICET) - Universidad Nacional de Quilmes (UNQ).
} 


\section{Introducción}

El Ensayo en defensa del sexo femenino ${ }^{3}$, publicado en Londres de manera anónima en el año 1696, constituye una de las primeras piezas filosóficas que pueden denominarse con propiedad feministas. Como su título lo indica, su objetivo principal es defender a las mujeres de acusaciones misóginas. De sus argumentos emerge una dicotomía que recibe elaboración filosófica en términos de una serie finita de pares contrapuestos, reunidos bajo el clivaje general naturaleza-historia. Esta díada concentra sobre sí las conclusiones filosóficamente más robustas de la obra y, a la vez, ofrece una vía retórica por la cual invertir la carga de la acusación machista.

Las mujeres inglesas escribieron muy pocas obras publicadas con anterioridad a la primera mitad del siglo XVII. Hay interesantes excepciones, como lo son los casos de Margaret Beaufort, Margaret Roper, Lady Anne Bacon (madre de Sir Francis), Mary Sidney condesa de Pembroke o Anne Askew. Destaca, entre ellas, la obra de Jane Anger (1560-1600) Her protection for Women, publicada en 1589. Anger fue la primera mujer que publicó una defensa completa del género femenino en inglés. Es el primero de un grupo de panfletos escritos entre 1589 y 1640 que han sido acríticamente aceptados como ejemplos tempranos de escritura feminista: escritos como los de Rachel Speght, Esther Sowerman o Constantia Munda (estos últimos, seudónimos).

Las décadas de 1640 y 1650 representan un punto de inflexión. Sólo en esas décadas las mujeres accedieron a publicar un número de obras que sobrepasaba cómodamente todo lo publicado con anterioridad. Aunque se ha asociado este crecimiento en las publicaciones femeninas con cierto carácter licencioso del régimen puritano posterior a la guerra civil inglesa, las publicaciones femeninas siguieron siendo un porcentaje ínfimo en comparación con las publicaciones de obras escritas por varones. Sin embargo, durante la segunda mitad del siglo XVII encontramos algunas de las figuras femeninas más conocidas del período, escritoras y filósofas como Bathsua Makin, Margaret Cavendish, Aphra Behn y Mary Astell.

Astell, nacida en Newcastle en 1666, llegó a Londres con tan solo 22 años, decidida a ganarse la vida como escritora. Su fe anglicana ortodoxa, su vínculo con intelectuales de la escuela platónica de Cambridge (especialmente con John Norris) y sus inclinaciones políticas conservadoras le permitieron granjearse la amistad y el patronazgo de varias mujeres relevantes del ámbito realista tory. Su período de mayor y más relevante producción intelectual, aproximadamente la quincena de años que se extienden entre 1690 y 1705, coincidió con la conformación, en torno a ella, de este grupo de mujeres que, influenciadas por la emergente cultura francesa de los salones (encarnada en ese entonces por Madeleine de Scudery y las preciéuces) y por las nuevas ideas en filosofía (ora el cartesianismo francés, ora el experimentalismo británico), trasladaron a la prensa los debates que normalmente llevaban entre ellas, sobre la naturaleza de la mujer, sobre la tiranía masculina o sobre las trampas del matrimonio.

\footnotetext{
${ }^{3}$ No conozco ninguna versión española de esta obra. Todos los pasajes citados aquí en español han sido traducidos por mí, tanto de esta obra como de A Serious Proposal to the Ladies.
} 


\section{El Ensayo, su autoría y su estructura general}

La obra que analizaremos es, precisamente, fruto de este colectivo femenino de discusión, intercambio de ideas y debate privado que floreció en Londres en la última década del siglo XVII y la primera del XVIII. Si bien posee unidad temática y argumental en sí misma, la obra también tiende vínculos sistémicos con las demás producciones intelectuales del círculo femenino astelliano. Tal es así, que durante cierto tiempo se la ha considerado una obra escrita por la misma Mary Astell. Hay algunos motivos que han inclinado a asumir que la autoría del texto corresponde a Astell. Hoy en día sabemos con certeza que durante estos años, Astell publicó anónimamente su primera y más conocida obra, A Serious Proposal to the Ladies for the Advancement of their True and Greatest Interest, cuya primera parte salio a la luz en 1694 y cuya segunda parte, considerablemente más extensa, se incorporó en la segunda edición de 1697. Esta obra, que parte de un diagnóstico de los privilegios masculinos sistemáticamente negados a las mujeres sobre la base de una disposición arbitraria de una sociedad patriarcal y androcéntrica, desarrolla una propuesta filosófico-pedagógica para mejorar la situación intelectual y social de las mujeres, basada fundamentalmente en el acceso de la mujer a la educación, pero una educación por y para mujeres exclusivamente. Esta idea general de organizar una institución que funcione a la vez como retiro religioso y como instituto educativo que nos presenta la primera parte de la Propuesta tenía como objetivo sustraer a las mujeres de los contextos sociales opresivos en los que inevitablemente se ven envueltas cotidianamente y colocarlas en un ambiente caracterizado por la sororidad y el cultivo de las virtudes intelectuales y morales. En la segunda parte, Astell desarrolla con mucho más detalle el método a seguir en esa institución, el cual está respaldado y articulado por una serie de directrices metafísicas, epistémicas y morales. Astell desarrolla una teoría acerca de la naturaleza del entendimiento, de la voluntad y de las pasiones de marcada influencia cartesiana y malebrancheana para luego articular la cuestión formativa y pedagógica con el dominio de la voluntad sobre las pasiones, la virtud y la perfección del alma como desiderata (en oposición a la mera búsqueda artificial de la belleza corporal que, a diferencia de la genuina perfección del alma y del carácter, tiene por objeto la representación de los otros, la mirada y la aprobación del varón, no la propia ante la mirada de Dios).

Ahora bien, esta propuesta pedagógica para las mujeres podría chocar rápidamente con la idea de su inferioridad e incapacidad para llevar a cabo actividades intelectuales. Evidentemente, si Astell defiende la educación de la mujer como su verdadero y más elevado interés, es porque rechaza la idea de que las mujeres sean naturalmente incapaces.

Aunque ha sido dicho por hombres más ingeniosos que sabios, y quizás más maliciosos que ninguno de los dos, que las mujeres son naturalmente incapaces de actuar con prudencia, o que están necesariamente determinadas a la insensatez, de ninguna manera debo reconocerlo; esa Hipótesis volvería impertinentes mis esfuerzos, porque entonces sería en vano aconsejar la una o emprender la reforma de la otra. Además, hay ejemplos en todas las edades que refutan suficientemente la ignorancia y malicia de esta afirmación. ${ }^{4}$

${ }^{4}$ ASTELL, A Serious Proposal to the Ladies, Part I, p. 16. El énfasis es nuestro. 
Como puede leerse en este pasaje, Astell rechaza la hipótesis de que la mujer sea naturalmente inferior al hombre y supone, para posibilitar su discusión, que si acaso fuera cierto que hay alguna incapacidad de la mujer en comparación con el hombre, entonces se trataría de algo adquirido y no natural, es decir, producto de ciertas tradiciones y costumbres arraigadas a lo largo de siglos que han privilegiado a los varones y relegado a las mujeres. Sin embargo, esta tesis es aceptada, precisamente, ex hipothesi, a efectos de poder explicar sus causas y sus concomitantes remedios. El ensayo que nos compete en esta oportunidad ocupa justamente ese lugar vacante, dado que es una discusión pormenorizada de la cuestión e intenta ser una demostración definitiva de que la presunta incapacidad femenina no es natural, sino adquirida, y por ende reversible. El Ensayo en defensa del sexo femenino, por ello, es una pieza teórica que, a primera vista, coordina armónica y sistemáticamente con las discusiones de Astell, lo cual hace plausible y entendible que durante tanto tiempo se haya creído una obra escrita por la misma Astell. Sin embargo, no parece ser así. Hay elementos teóricos y textuales de esta obra que, a mi entender, parecen indicar con cierta plausibilidad que la autoría del texto no corresponde a Astell (aunque su figura y sus ideas hayan sido muy probablemente su fuente de inspiración), sino a una de las integrantes de su círculo intelectual, Judith Drake ( $† 1723$ ), de quien por otro lado sabemos muy poco. ${ }^{5}$

Aunque a primera vista el Ensayo es compatible con la Propuesta de Astell y, en términos generales, ambas discusiones se complementan la una a la otra, una mirada más detenida de quienes conozcan en detalle las ideas y la escritura de Mary Astell, encontrarán que algunos de los elementos teóricos del primero no son idénticos a los de la segunda y que algunas de las ideas centrales de ésta última, están casi completamente ausentes en el primero. Es conocida la influencia determinante del neoplatonismo en la obra de Astell, cuya metafísica le sirve para organizar la doctrina cristiana que tanto peso tiene en su sistema. Este neoplatonismo cristiano se articula en la obra astelliana con una recepción y reelaboración de las teorías racionalistas de Descartes y Malebranche. Quizás por ello, Astell no siente especial predilección por la filosofía experimentalista y empirista de sus compatriotas ingleses y, en especial, es muy crítica de la filosofía de John Locke, quien era uno de los intelectuales más conocidos e influyentes de la época. Astell se oponía prácticamente a todas sus opiniones políticas, gnoseológicas y metafísicas. Sin embargo, en el Ensayo encontramos algunas referencias a la filosofía experimental de la época (como elogios a Robert Boyle y a la Royal Society) y especialmente una aceptación explícita de la teoría lockeana del entendimiento, incluyendo el rechazo del innatismo tan caro al cartesianismo; elementos que confrontan abiertamente con las principales líneas racionalistas adoptadas por Astell. En cambio, son mucho menores las referencias a Dios, al punto de que hay únicamente un argumento teológico en todo el Ensayo y es despachado rápidamente en un breve párrafo, dado que, en palabras de la autora: "no pretendo hacer de este un argumento religioso".

Por otro lado, hay un elemento textual adicional, aunque completamente independiente de cuestiones teóricas o filosóficas, que parece también indicarnos la autoría del texto. Entre la dedicatoria y el prefacio escritos por la autora y el Ensayo propiamente dicho, encontramos un breve poema en tres páginas en el que presenciamos un sentido elogio de la autora, de sus virtudes, su ingenio, de cómo ha disipado las nubes y la neblina con la

\footnotetext{
${ }^{5}$ Sabemos que en 1707 prologó la publicación póstuma de la obra médica de su marido, por lo que tenemos que suponer que estaba versada en medicina y anatomía.

${ }_{6}^{6}$ DRAKE, An Essay in Defence of the Female Sex, p. 11.
} 
claridad radiante de la verdad, sobre cómo el género femenino brilla bajo el reflejo de su luz, entre muchas otras cosas. Esta alabanza, tan lisonjera como es, está firmada por James Drake (1667-1707), médico, miembro de la Royal Society, autor del Anthropologia Nova or a New System of Anatomy (1707), Jacobita y panfletista tory, con quien Judith Drake contraería matrimonio, y con quien tendría dos hijos, Ann (nacida en 1700) y James (nacido en 1703). Es altamente probable, por ende, que ese elogio tan amoroso y adulador esté dirigido nada menos que a la futura madre de sus hijos.

A pesar de estas cuestiones históricas respecto de la autoría del texto, que sin duda tienen su relevancia, y que tienden a inclinarnos a rechazar a Astell como la pluma detrás del Ensayo, más interesante resulta pensar que se trata de una serie de obras escritas por distintas mujeres que pensaban colectivamente un conjunto de problemáticas de género que las convocaba a todas y cada una de ellas, que debatían, se leían y se discutían entre sí. En ese sentido, tan interesante como estudiar y señalar las diferencias de tono, de contenido o de forma entre sus aportes individuales, resulta también la tarea de indagar las opiniones coincidentes, las ideas que todas en mayor o menor medida compartían y las propuestas adoptadas en común. De hecho, no es raro encontrar que escribieran obras sobre las mismas temáticas: por ejemplo, Mary Astell publicó su Some Reflections Upon Marriage en 1700 y Lady Mary Chudleigh su The Ladies' Defense tan sólo un año después, en el que también se concentra en un análisis de la institución del matrimonio desde el punto de vista femenino, de los privilegios masculinos de dicha institución y de la prerrogativa femenina de evitar el matrimonio y dedicarse a cultivar su propio mérito individual.

En ocasiones, la obra de este grupo de mujeres se ha considerado "panfletaria". Si por ello se entiende que sus escritos carecen de cierta sistematicidad filosófica, se estaría incurriendo en un equívoco, como ya hemos señalado. La naturaleza integral de sus obras nos habla de un pensamiento filosófico desarrollado, si bien con una inclinación preminentemente social y política, como puede observarse revisando algunos de sus títulos más conocidos. Sin embargo, esta caracterización llama la atención respecto de los registros discursivos que despliegan estos escritos. En tanto dispositivos literarios, están implicados en la intervención de una voz femenina al interior de debates puntuales que habían alcanzado el estatuto de la opinión pública. Muchos de ellos, además, están involucrados en defender la legitimidad misma de dicha intervención. Esta situación nos advierte sobre la mixtura que hay en estas obras entre la argumentación filosófica y el estilo retórico. A diferencia de otras obras más conocidas y comentadas, especialmente el A Serious Proposal to the Ladies de Astell, el ensayo de Drake que analizaremos a continuación ha recibido menos atención entre intérpretes, pero creo que, si bien carece del carácter programático de aquel, sí resulta un ejemplo más interesante de esta confluencia de géneros retóricos y argumentación filosófica que acabo de mencionar.

El Ensayo fue publicado anónimamente: "en una carta para una Dama, escrita por una Dama”. Está precedido por dos textos de la pluma de la autora: (a) por una dedicatoria a la Princesa Ana de Dinamarca (más tarde Reina de Inglaterra) y (b) por un prefacio. Allí quedan establecidas varias cuestiones previas. Por un lado, que se trata de un escrito diseñado para y dirigido a un público femenino; por otro, que busca reivindicar el honor del sexo femenino, y que los objetivos concretos por medio de los cuales se alcanzará ese fin son dos:

${ }^{7}$ Cf. DURAN, Eight women philosophers. Theory, politics, and feminism, p. 77. 
el de reducir los sexos a un pie de igualdad y, con ello, el de elevar al femenino a una igualdad con el masculino, por medio de argumentos racionales y no por mera declamación. En consonancia con esto, la autora aclara que a la hora de argumentar hará uso, por un lado, de la Razón y, por el otro, de la Observación.

El título pareciera presagiar que su finalidad haría del texto, desde el punto de vista de la clasificación aristotélica de los géneros retóricos, un discurso forense o judicial, es decir, un discurso en donde se debate lo justo o lo injusto de una acusación. Sin embargo, conviven a lo largo del texto distintos géneros retóricos. En efecto, el ensayo comienza presentando la acusación que los varones hacen a las mujeres y se dispone a defenderlas, pero la discusión filosófica de esta cuestión da pie luego a una secuencia de discursos epidícticos, es decir, por un lado, a un elogio de las virtudes femeninas y, paralelamente, a una censura de los vicios masculinos. Finalmente, la discusión derivará hacia lo que la clasificación aristotélica denominaría género deliberativo, es decir, un discurso evaluativo de lo conveniente o perjudicial de ciertas relaciones sociales entre varones y mujeres, en el cual la autora no sólo dirá que es aconsejable que los varones se relacionen con las mujeres si pretenden enmendar aquellas cualidades que han sido previamente censuradas, sino que, además, intentará disuadir a las mujeres de que se vinculen con ciertos varones, cuya compañía no puede sino ser perjudicial para ellas.

Lo que motiva y articula la sucesión de estos tres lugares distintos de persuasión retórica son precisamente las conclusiones a las que se arriba en cada instancia por medio de la aplicación de argumentos filosóficos. De hecho, podría sostenerse que las dos articulaciones centrales del ensayo reposan en sendos argumentos filosóficos que se acomodan, respectivamente, a la clasificación metodológica que se adelanta en el prefacio: siendo el primero de ellos un conjunto de argumentos basados "en la Razón”, mientras que el segundo conjunto de argumentos hace lo propio sobre la base de una aguda "Observación" de la sociedad de la época y sus distintos caracteres.

A continuación me concentraré en la primera secuencia de argumentos y su respectiva articulación con la ofensiva retórica de Drake. En el proceso podremos apreciar cómo opera el clivaje que funciona como hilo conductor: la distinción entre naturaleza e historia. Debido a los límites de espacio, un análisis completo de la obra quedará pendiente para otra ocasión.

\section{Primeros argumentos: “a partir de la Razón”}

El primer lugar de persuasión retórica que asume el texto es de tipo forense, pues se trata de la defensa ante una acusación común de la que son objeto las mujeres: se trata de decidir si puede o no puede decirse con justicia que el tiempo que un caballero ingenioso pasa en la compañía de mujeres ha sido mal empleado. Esta acusación, afirma la filósofa, ha de examinarse sobre la base de los fines y propósitos que persigue en general la interacción social: el beneficio y el placer, o en otras palabras, el progreso del entendimiento y la diversión y relajación de las preocupaciones y de las pasiones.

El esquema argumentativo de esta primera defensa posa sobre una disyunción excluyente. Si las mujeres no estuviesen calificadas para la conversación y la amistad sería sólo por carecer de las virtudes que las hacen posibles (intelectuales y morales: sensatez, buen 
natural, fidelidad, integridad). Pero de ser así, a su vez, esto sería o bien (a) porque la naturaleza no ha sido tan liberal como para depositarlas en ellas, o bien (b) porque no se ha tomado el cuidado adecuado para cultivar dichos dotes. Al presentar el argumento en forma dicotómica, Drake decide dirigir una primera batería de argumentos contra la primera alternativa, para concluir que no se trata de que las mujeres estén naturalmente descalificadas (es decir, que carezcan por naturaleza de aquellas virtudes). Estos argumentos, que discuten la naturaleza femenina, entonces, se construyen, como dice ella, "a partir de la Razón”. Se trata de dos argumentos distintos.

1) El primero es un argumento religioso, pero sólo es brevemente tratado, sin pormenorizar, dado que, como adelantamos, a diferencia de Astell, a Drake no le interesa tanto montar su discusión sobre premisas teológicas.

Para mencionarlo rápidamente digamos que el argumento se constituye a partir de la noción de Providencia Divina y presenta la siguiente forma: Las mujeres fueron creadas por Dios para ser las compañeras de los varones y no únicamente para la reproducción -si fuera sólo para eso, Dios podría haber creado sin obstáculo alguno otras formas de continuar la especie. Si eligió ésta, consecuentemente, es porque la compañía femenina es lo que conduce al varón a su felicidad -que es el único fin de la creación.

2) El segundo, que por contraste podríamos llamar argumento filosófico, está mucho más desarrollado, por lo que resulta más interesante y complejo. En realidad se trata de dos argumentos distintos, que en esencia giran en torno a la distinción dualista entre alma y cuerpo. El primero de ellos, que podríamos llamar el argumento metafísico, sostiene que, separada del cuerpo, no podemos encontrar ninguna distinción de género en el alma. Aunque algunas intérpretes han destacado la influencia del dualismo cartesiano en el pensamiento filosófico de Astell, aquí en el caso de Drake es interesante señalar que la otra premisa que, junto con el dualismo, permite alcanzar esta conclusión es una tesis anti-innatista. En efecto, afirma que al no haber ideas innatas, todas nuestras nociones y todas nuestras virtudes derivan de los sentidos externos, o bien inmediatamente, o bien mediante reflexión. Consecuentemente, los rasgos del carácter que distinguen en general varones de mujeres no son innatos, ni están grabados naturalmente en el alma.

Pero aunque la razón muestre que no hay una determinación metafísica del alma que distinga géneros, alguien podría suponer que la constatación de la distinción (y la concomitante inferioridad femenina) tenga lugar en el ámbito de la experiencia y, por ende, que esté relacionada con diferencias anatómicas u orgánicas propias de los cuerpos de varones y mujeres. Pero la filósofa presenta inmediatamente un nuevo argumento dirigido a esta cuestión.

Este segundo argumento, que podríamos denominar argumento físico, tiene como fin mostrar que no hay diferencia en la organización de nuestros cuerpos, ni en la de nuestros cerebros, ni en la de los espíritus animales que son los instrumentos inmediatos de la sensación tanto en mujeres como en varones. Drake arguye que no hay impedimentos naturales en la estructura de los cuerpos femeninos cuya existencia pueda defenderse racionalmente sobre la base de la experiencia: las mujeres emplean todas sus facultades naturales al igual que los hombres.

Drake explota en su favor distintos tipos de experiencia, lo que hace que el argumento se ramifique en tres direcciones diferentes que finalmente convergen. En primer lugar, tenemos una confirmación que procede de la experiencia de los animales: si observamos 
las criaturas que menos se desvían de la naturaleza, es decir, sin las restricciones de la costumbre o las leyes, no podemos detectar diferencia de entendimiento entre machos y hembras. Criaturas guiadas por la pasión, que desconocen las diferencias de educación o las tendencias propias del prejuicio, manifiestan capacidades similares independientemente de sus sexos.

En segundo lugar, esta igualdad física queda confirmada por la experiencia de la bumanidad, y esto en dos sentidos diferentes. Primero, destaca Drake que si considerásemos a la gente de campo y a los jornaleros, es decir, a las clases trabajadoras, advertiríamos que en ellos la condición de ambos géneros está nivelada (e incluso que las mujeres superan a los varones en presteza y cortesía). Segundo, también se dice que en otras naciones vecinas más adelantadas en lo que hace a la igualdad de derechos, como en Holanda, se percibe mayor equidad entre varones y mujeres que en Inglaterra. Ambos ejemplos en conjunto sugieren que, en clases más privilegiadas, las diferencias entre varones y mujeres radican precisamente en una diferencia de privilegios, y que la desigualdad en estos privilegios es irreductible a cualquier supuesta inferioridad natural entre sexos, puesto que es producto de las costumbres.

En tercer y último lugar, Drake no sólo emplea la experiencia para desmentir la supuesta inferioridad femenina o la supuesta inadecuación femenina para la realización de ciertas actividades, sino que además invierte la situación en favor de las mujeres a partir de una descripción de la respectiva conformación de los cuerpos: las mujeres, más delicadas físicamente, han de estar naturalmente equipadas para el pensamiento y el ejercicio de la mente (asociado a virtudes como el ingenio y la prudencia, la ternura y el cuidado), y los varones, más robustos y fornidos, naturalmente equipados para las actividades físicas: la acción y el trabajo.

La conclusión general que arroja esta batería de argumentos filosóficos es que la posición de inferioridad en la que se hallan las mujeres con respecto a los varones no radica en ningún vicio o incapacidad natural del género femenino, sino que es, hasta donde la razón y la observación lo indican, el producto de cierto tipo de socialización, en la que los varones asumen un rol dominante y las mujeres, uno sumiso.

\section{La dicotomía Naturaleza-Historia}

Este repaso somero por la estructura general de los primeros argumentos permite poner de manifiesto las características de una dicotomía de género que hacen de este texto un genuino antecedente de las discusiones feministas contemporáneas. Esta apreciación inicial se ve ratificada a medida que uno avanza en la lectura de la obra, puesto que el Ensayo no sólo encara un análisis crítico de dicha dicotomía de género, sino que sostiene además algunos principios que bajo estándares actuales también son claramente feministas. Aunque hay disputas teóricas sobre cómo definir el feminismo, en general podríamos aceptar como definición preliminar la conjunción de tres tesis fundamentales ${ }^{8}$ : una descriptiva, una prescriptiva y otra práctica. La primera es descriptiva porque se trata de una afirmación fáctica, empíricamente constatable, y que dice que en todas las sociedades las mujeres están en una situación desventajosa o desfavorable respecto de los varones, que como colectivo se

${ }^{8}$ Cf. MAFFIA, Contra las dicotomías: feminismo y epistemología crítica, [s/f]. 
encuentran en situaciones de mayor precariedad, inseguridad o vulnerabilidad comparativa. La segunda es prescriptiva porque se trata de una afirmación valorativa. Esta tesis asevera que no es justo, que no está bien que las mujeres de todas las sociedades estén comparativamente peor, como colectivo, en oposición a los varones; que se trata de algo que no debería ocurrir. Sobre la base de esta apreciación axiológica se funda el tercer enunciado que constituye al feminismo, uno de carácter práctico, es decir, que involucra un compromiso moral para confrontar con y evitar la subordinación jerárquica sistemática de las mujeres respecto de los varones, por el mero hecho de ser mujeres y varones.

Una dicotomía de género es una distinción dual entre pares opuestos de conceptos que ubica de cada lado de la distinción, respectivamente, al colectivo entero de los varones y de las mujeres. Se trata, en otras palabras, de una generalización que recorta y divide el conjunto de la sociedad de manera exhaustiva y excluyente sobre la base de un principio organizador binario que disgrega según el sexo (y el género correspondiente) de las personas. Este principio organizador, asimismo, no sólo está sexualizado, sino que también recibe una carga valorativa, de modo tal que el lado femenino de la dicotomía es infravalorado o valorado negativamente respecto de su par masculino. Mientras que los varones han sido tradicionalmente asociados a cualidades como la racionalidad, la abstracción, lo universal o la actividad en la esfera pública, a las mujeres se las ha asociado tradicionalmente con lo emocional, lo particular, lo concreto, la esfera del ámbito privado o doméstico.

En ese sentido, el Ensayo en defensa del sexo femenino es una obra que, a pesar de sus 325 años, resulta todavía hoy una obra visiblemente feminista, en tanto que pone de manifiesto esta dicotomía entre varones y mujeres en distintos ámbitos de la realidad (político, social, económico, educativo) y afirma sin matices que las opiniones y las conductas de los varones hacia las mujeres que se basan en estas categorías resultan injustas y moralmente despreciables, precisamente porque no pueden justificarse en la naturaleza misma de la feminidad. Se trata, por el contrario, de un sistema social y político opresivo erguido a través del uso ilegítimo de la fuerza y sostenido por un aparato ideológico androcéntrico que opera por igual sobre la mente (y los cuerpos) de varones y mujeres.

Lo interesante de la obra es que no se limita sólo a señalar lo que podríamos denominar la naturaleza ideológica de esta dicotomía, sino que lleva a cabo un diagnóstico de la situación, ofreciendo elementos históricos y filosóficos para una reconstrucción conjetural de la misma, con la intención de desarticular las creencias y las opiniones misóginas que operan en el sentido común respecto de sus más tradicionales (aunque insostenibles) fundamentaciones. Para ello, Drake replantea la dicotomía de forma tal que pueda ponerse al desnudo su componente ideológico androcéntrico, arbitrario e injustamente misógino. Ya no se trata de una dicotomía de género, pero sí de una dicotomía que asume una faz feminista, pues pretende retratar el viraje entre una situación original de igualdad natural entre los sexos y una historia social general de la civilización caracterizada por el dominio inicuo de los varones, que han humillado servilmente a las mujeres, relegándolas cruelmente a un lugar subalterno que sofoca y deshonra sus potenciales naturales.

La dicotomía naturaleza-historia recoge dentro de sí un listado de conceptos y categorías que le permiten a Drake no sólo pensar el sistema androcéntrico de opresión a la mujer sino también elaborar, como veremos, lugares retóricos de discusión a partir de los cuales atacar, sobre la base de una noción reformulada de naturaleza en general y naturaleza femenina en particular, la historia de tiranía y usurpación masculina, invirtiendo en el proceso 
la carga de la prueba de la acusación machista que recae sobre la mujer y cuyo análisis crítico es el objeto del Ensayo.

La naturaleza está asociada a una fase primitiva de la historia en la que varones y mujeres mantenían relaciones de igualdad y reciprocidad entre sí. Al tratarse de un estado en donde varones y mujeres yacían en igualdad, libertad e independencia los unos respecto de los otros, fácilmente podría hacernos pensar en una suerte de estado de naturaleza originario en sentido contractualista, en el que la única subordinación era la de todo el género humano a Dios soberano. Por ende, se trata de un estado en el que reina la razón y en el que se cultivan las bellezas intelectuales y morales del alma. Allí regían, por ende, las virtudes morales del compañerismo y la amistad.

A este estado se le opone un estado ulterior, que ha sido el producto de las maquinaciones y especulaciones de los hombres, quienes han hecho uso de la fuerza física que naturalmente los caracteriza para monopolizar el poder e imponer un orden social caracterizado por la sujeción de la mujer. Los varones, que se erigen como los soberanos y principales actores de la historia de la humanidad, ejercen ese poder especialmente sobre los cuerpos de las mujeres, no sólo sexualizando una política de segregación sino socializando a las mujeres en la ignorancia respecto de virtudes intelectuales superiores y destinándolas únicamente al cuidado y regulación de sus cuerpos, haciendo de la belleza física el único y principal interés femenino, para deleite del varón. Estas nuevas directrices que regulan la vida en comunidad, por ende, no se basan en una adecuada valoración de la naturaleza espiritual del ser humano (intelectual y moral), y por lo tanto no se aplican bajo la autoridad de la razón (o, para el caso, de Dios), sino únicamente bajo la autoridad de la fuerza masculina primero y del hábito después. Precisamente, el hábito logra invisibilizar esas relaciones de iniquidad entre varones y mujeres y hace difícil de advertir el dominio cruel y tiránico que los hombres ejercen sobre las mujeres. Pero que algo se haya vuelto habitual, que esté sancionado por la costumbre, las leyes o las tradiciones humanas, no lo hace inmediatamente legítimo. Por el contrario, esta dicotomía permite emplear el constructo filosófico de un estado de naturaleza original como criterio de evaluación de la realidad histórica que atraviesan las mujeres, poniendo de manifiesto su carácter esencialmente usurpador y deleznable.

Es cierto que difícilmente pueda demostrarse que haya existido históricamente una instancia original o primitiva de estas características. Sin embargo, no se trata de una afirmación histórica, sino conceptual, cuya utilidad radica en su potencial retórico. A diferencia del discurso científico o filosófico, la retórica no pone su principal interés en la conexión entre el discurso y la verdad de las proposiciones, sino que lo coloca explícitamente en la comunicabilidad de lo que dice el orador a su auditorio. El plano de referencia del discurso no se sitúa "en las cosas mismas", sino que se sitúa en las opiniones, en el sistema comunitario de creencias a partir del cual, como criterio, se instituye la argumentación. Las opiniones y el sentido común de un auditorio forman un sistema que duplica la realidad y opera, en el nivel lingüístico y pragmático, como la experiencia lo hace en el nivel epistémico, es decir, como criterio de verificación. De ese modo, la retórica puede probar la credibilidad de una tesis mediante una adecuada confrontación con el sistema de opiniones y creencias comunes. En ese sentido, la retórica como método se presenta como un instrumento de selección y justificación de enunciados persuasivos, pero que además de contemplar la relación epistémica que ha de haber entre los enunciados y las cosas sobre las que refieren, a su vez no puede desatender la relación persuasiva que se da entre el investigador y el auditorio 
cuyas opiniones pretende torcer a su favor. En este caso, como hemos dicho, el Ensayo es una obra escrita por una mujer para un auditorio femenino, por lo que la dicotomía resultará fructífera retóricamente para la conformación de un ethos y de un pathos femenino, que permitirá redefinir filosófica y retóricamente el carácter femenino, reconfigurando en el proceso nuevos sentidos y nuevas agencias para las mujeres, de cara a la posibilidad de ejercer una influencia que revierta su situación de subordinación, e ideando un nuevo lugar que potencialmente puedan ocupar las mujeres en la sociedad de su época y los cambios positivos que estas reconfiguraciones traerían aparejadas.

\section{Giro epidíctico: elogio de las mujeres y censura de los varones}

Si seguimos fielmente la Razón, ésta nos muestra que la supuesta inferioridad de las mujeres no es tanto una incapacidad natural, como una desventaja impuesta por las costumbres y los procesos de socialización que seleccionan y organizan la educación que recibirán los distintos miembros de la sociedad según su sexo. Sin embargo, Drake evita la conclusión de que las diferencias se explican únicamente por la disparidad educativa. Por el contrario, el Ensayo comienza en este punto una larga exposición de carácter retórico en el que se responsabiliza directamente a los varones, quienes ejercen un poder político y social sobre las mujeres y ahogan sus posibilidades de progreso individual. Por ende, ya no es posible que se afirme, en desmedro de las mujeres, que carecen de virtudes intelectuales o morales meramente por causa de la educación que han recibido, sino que la cuestión ahora es indagar por qué reciben la educación que reciben y quiénes son los verdaderos responsables de la situación desventajosa por la que atraviesan.

Los hombres rara vez instan esta causa en contra nuestra [i.e.: la disparidad educativa], aunque es la única que les da alguna ventaja sobre nosotras en cuanto a comprensión. Pero no sirve a su orgullo, no hay honor que ganar con ello: porque un hombre no debe valorarse más por ser más sabio que una mujer, si debe su ventaja a una mejor educación y mayores medios de información, de lo que debería jactarse de su coraje por golpear a un hombre cuando sus manos estaban atadas. ${ }^{9}$

En efecto, Drake sostiene que la educación de las mujeres de su época no es tan deficiente como comúnmente se piensa. De hecho, durante los primeros años de vida es en términos generales similar: tanto a las niñas como a los niños se les enseña a leer y a escribir en sus años más tiernos. Sin embargo, es a partir de los siete años, afirma Drake, luego de haber sido introducidos en los rudimentos de la alfabetización, que se los separa en dos grupos, por criterios sexuales. A los niños se los manda a las escuelas de gramática, en donde profundizarán sus saberes de la lengua materna, en donde seguramente se les enseñará el francés y los rudimentos del latín, en donde también podrán aprender matemática, geografía o historia. Las niñas, en cambio, son enviadas a internados, en donde la educación se concentrará en el cultivo de ciertos talentos (accomplishments) tales como el tejido, el canto, la

${ }^{9}$ DRAKE, An Essay in Defence of the Female Sex, p. 20. La aclaración en negrita es un añadido nuestro. 
música, el dibujo y la pintura. Todos estos talentos, además, están destinados a agradar a los varones, sean sus padres, sus pretendientes, o sus futuros esposos.

Los hombres, tiranos y cobardes, mantienen a la mujer en la ignorancia y con ello dan testimonio de la crueldad que les caracteriza. Estos pasajes, de alto vuelo retórico, retratan con claridad meridiana una situación de explotación machista enraizada prácticamente en el origen mismo de la historia de la civilización humana y expresan de manera inequívoca la ya mencionada dicotomía naturaleza-historia que se perfila en el texto:

Sólo pueden ser tiranos los cobardes. Porque nada hace que una de las partes deprima servilmente a otra, sino su temor de que en un momento u otro puedan volverse lo suficientemente fuertes o valientes como para igualar, o incluso superar, a sus amos. Este es nuestro caso; porque los hombres, siendo conscientes tanto de las habilidades de la mente en nuestro sexo, como de la fuerza del cuerpo en el suyo propio, comenzaron a ponerse celosos de que nosotras, que en la infancia del mundo fuimos sus iguales y socias en el dominio, pudiéramos en el proceso del tiempo, por sutileza y estratagema, convertirnos en sus superiores; y por lo tanto comenzaron a hacer uso de la fuerza (origen del poder) para obligarnos a una sujeción que la Naturaleza nunca quiso; e hicieron uso de las bondades que les dio la Naturaleza para sacar provecho de aquellas que nos dio a nosotras. Desde ese momento se han esforzado en entrenarnos por completo en la indolencia y la ignorancia; como los conquistadores suelen hacer con aquellos que reducen por la fuerza, para desarmarlos, tanto de coraje como de ingenio; y en consecuencia hacerlos renunciar dócilmente a su libertad y someter abyectamente sus cuellos a un yugo servil. ${ }^{10}$

Drake apoya esta opinión con dos casos ejemplares, uno mítico y otro real. El ejemplo mítico lo provee la historia de las Amazonas, un pueblo compuesto exclusivamente por mujeres. Las Amazonas resultaron un interesante objeto de reflexión filosófica feminista a lo largo de toda la modernidad. Para Drake, el hecho de que las Amazonas no hayan querido compartir en sociedad con los varones, aunque tuvieran que encontrarse con ellos periódicamente para garantizar la reproducción de sus ciudadanas, es un índice de que los beneficios que podrían extraer de una asistencia mutua no superaban los perjuicios provenientes de la voluntad de dominio que los varones manifiestan hacia las mujeres. Si pudiendo haberlo hecho, decidieron mantener su distancia, es porque no querían aceptar la subordinación servil. En otras palabras, su convicción de vivir en sociedad separada habla de la tendencia masculina a suprimir su libertad. Esta misma subordinación servil puede apreciarse incluso en Inglaterra, a pesar de las comodidades con las que allí cuentan las mujeres: "grilletes de oro siguen siendo grilletes y la seda que vestimos nunca podrá hacerlos tan cómodos como la libertad"11.

La segunda situación histórica que presenta Drake en apoyo de su diagnóstico crítico y de su feroz censura al régimen cruel al que las mujeres son sometidas está comprendida en

${ }^{10}$ DRAKE, An Essay in Defence of the Female Sex, pp. 20-21.

${ }^{11}$ DRAKE, An Essay in Defence of the Female Sex, p. 25. 
un comentario sobre la Ley Sálica francesa. Aquí resulta interesante no sólo la idea de que hubo un tiempo primitivo en el que las mujeres fueron libres, sino la caracterización del poder masculino como irracional o irrazonable (lo cual congenia muy bien con la idea de que se trata, además, de un poder tirano y cruel) y la agudeza crítica de poner en tela de juicio los relatos históricos que han llegado hasta nuestros días, dado que todos ellos han sido escritos por hombres, es decir, por sujetos que hemos de suponer tienen a priori una agenda misógina.

Los franceses son un pueblo ingenioso, y quienes confeccionaron esa ley sabían bastante bien que nosotras no éramos menos capaces de reinar y gobernar bien que ellos; pero sospechaban que si el Poder Real caía a menudo en manos de las mujeres, éstas favorecerían su propio sexo y, con el tiempo, podrían devolverles su libertad primitiva e igualdad con los hombres, y así romper el cuello de esa autoridad irrazonable que tanto afectan sobre nosotras; y por eso hicieron esta Ley para prevenirlo. Los historiadores nos dicen otras razones, pero no pueden ponerse de acuerdo entre ellos, y como los hombres son partido en contra nuestra, su evidencia puede ser rechazada con justicia. A decir verdad, señora, no sé cómo probar todo esto a partir de registros antiguos; porque si alguna historia fue escrita antiguamente por mujeres, el tiempo y la malicia de los hombres han conspirado eficazmente para suprimirlas. ${ }^{12}$

Una vez desenmascarada la verdadera naturaleza de la situación de superioridad de los varones, Drake inicia un derrotero retórico en el que se encargará de elogiar las virtudes que las mujeres pueden cosechar incluso en este contexto de opresión masculina y de censurar, a su vez, a los varones, que por acción u omisión suelen desperdiciar o echar a perder los beneficios que recibieron de una educación liberal que es sistemáticamente negada a las mujeres.

Aunque privadas de una educación académica formal, hay muchas mujeres que cuentan con los medios para educarse de manera autodidacta. Por lo general las mujeres de Inglaterra, nos dice Drake, sólo manejan el inglés y en algunos casos (como el suyo) un poco de francés. Pero cuentan a su favor con una próspera industria editorial, que no sólo las coloca al alcance de importantes obras de autores británicos en prosa, poesía o teatro (Shakespeare, Bacon, Dryden, Milton son algunos de los nombres que hacen aparición en el texto) sino que además les ofrece buenas traducciones al inglés de autores extranjeros, tanto antiguos (Aristóteles, Platón, Ovidio, Horacio, Virgilio, Plutarco, Séneca, Cicerón son algunos de los nombrados), como modernos (Montaigne, La Rochefoucauld, St. Evremond). En ese sentido, Drake considera que a pesar de la disparidad en educación, y a pesar del monopolio arbitrario y tiránico que los varones tienen de las ciencias y la academia, no hay excusas para una mujer bien posicionada que desee instruirse, siempre que tenga la ambición de hacerlo.

Los hombres, por otro lado, que sí han recibido una educación liberal tampoco tienen forma de excusarse cuando echan a perder esos beneficios. Drake presenta dos casos ejemplares a través de dos arquetipos sociales de la época: el pedante (pedant) y el escudero

${ }^{12}$ DRAKE, An Essay in Defence of the Female Sex, pp. 22-23. 
(country squire). El primero, debido a su vida retirada e inactiva, rechaza todo tipo de negocio y permanece a tal punto en constante conversación con la antigüedad, que se vuelve una momia egipcia, extrañada e ignorante de los asuntos domésticos y de las costumbres de su propia época y país. El segundo, en cambio, ha heredado de sus ancestros los medios necesarios para dedicarse a tonterías y desperdicia su educación hablando todo el día de sus caballos, sus perros y halcones, discutiendo sobre cerveza y pedigrí, para el tedio de su auditorio.

Drake concluye que la supuesta inferioridad intelectual y moral de las mujeres no puede deberse en sí ni a la naturaleza ni tampoco a la desigualdad en la educación, como suele decirse, pues incluso aceptando las desventajas con las que debe lidiar una mujer en comparación al varón, a menudo sucede que aquellas están en condiciones de suplirlas tanto como estos de desperdiciarlas. Por lo tanto, las cualidades negativas y los vicios que los varones atribuyen a las mujeres no se deben sino a que éstos son adversarios mezquinos, que gustan más de cultivar el escándalo y la difamación que las razones y los argumentos sólidos. En efecto, Drake sostiene que los varones imputan a las mujeres una larga lista de faltas e imperfecciones que en realidad están extraídas del catálogo de sus propias insensateces y vicios, volviéndolas hacia ellas: vanidad, impertinencia, envidia, hipocresía e inconstancia. Cada uno de estos vicios que se atribuyen comúnmente a las mujeres puede ser críticamente revisado, de manera tal de restituirlos a sus verdaderos dueños, los hombres, si se hace una cuidadosa observación de las costumbres y los comportamientos de cada sexo. Esto da pie a una nueva secuencia de argumentos, cuyo análisis excede los límites de este trabajo.

\section{Referencias bibliográficas}

Anónimo [ASTELL, M.]. A Serious Proposal to the Ladies, for the Advancement of their True and Greatest Interest, in Two Parts. London: printed for R. Wilkin, 1967.

Anónimo [DRAKE, J.], An Essay in Defence of the Female Sex in which are inserted the Characters of a Pedant, a Squire, a Beau, a Vertuoso, a Poetaster, a City-Critck, etc.. London: printed for A. Roper and E. Wilkinson, 1969.

ARISTÓTELES. Retórica. Introducción, traducción y notas de Q. Racionero. Madrid: Gredos, 1999.

DURAN, J. Eight women philosophers. Theory, politics, and feminism. Chicago: University of Illinois Press, pp.1-133, 2006.

EALES, J. Women in Early Modern England. Londres: UCL Press, 1998.

MAFFIA, D. Contra las dicotomías: feminismo y epistemología crítica. Buenos Aires: Instituto Interdisciplinario de Estudios de Género, UBA, 2008.

PATEMAN, C. El contrato sexual. Introducción de María-Xosé Agra Romero, traducción de Ma. Luisa Femenías. Barcelona: Anthropos, Universidad Autónoma Metropolitana Iztapalapa, 1995. 
PAUL, M. Marketing Women's Writing in Eighteenth-Century England: The Consideration of Audience in the Works of Mary Astell, Lady Mary Wortley Montagu, and Frances Burney. Tesis Doctoral, California State University, 2005.

STUBBS, N. Mary Astell and Margaret Fuller: rhetorically redefining the conduct of women. Tesis Doctoral, California State University, 2005.

VERSCHUEREN, J. Para entender la pragmática. Versión española de E. Baena y M. Lacorte. Madrid: Gredos, 2002. 